\title{
Relation between angiotensin-converting enzyme II genotype and atrial fibrillation in Japanese patients with hypertrophic cardiomyopathy
}

Received: December 10, 2001 / Accepted: January 25, 2002

\begin{abstract}
Atrial fibrillation (AF) occurs in about 20\% of patients with hypertrophic cardiomyopathy (HCM). HCM patients with AF have an increased risk for clinical decline and thromboembolism. In addition, AF is known to be associated with the atrial renin-angiotensin system (RAS). However, the relation between AF and the RAS in HCM has not been investigated. We genotyped the insertion/ deletion (I/D) polymorphism of the angiotensin-converting enzyme $(A C E)$ gene in $138 \mathrm{HCM}$ patients (26 with AF, 112 with sinus rhythm). Distribution of the $A C E$ genotypes (DD, ID, and II) among the total HCM patients was $15 \%$, $46 \%$, and $38 \%$. AF was documented in 3 patients with the DD genotype, 7 with the ID genotype, and 16 with the II genotype ( $P<0.03$ vs. sinus rhythm group). The odds of AF were 3.2-fold greater in patients with the II genotype than in those with the other genotypes $(P=0.009,95 \%$ confidence interval $=1.3-7.8)$. Kaplan-Meier curves examining the time to the first documented AF event showed a significant difference between genotypes during the follow-up period (mean 116 months, $P<0.05$ ). These findings suggest that the II genotype of the $A C E$ gene is a significant risk factor for AF in patients with HCM.
\end{abstract}

Key words Hypertrophic cardiomyopathy · Atrial fibrillation · Angiotensin-converting enzyme · Reninangiotersin system $\cdot$ Polymorphism

\section{Introduction}

Atrial fibrillation (AF) is known to occur in $20 \%$ of patients with hypertrophic cardiomyopathy (HCM) (Maron et al.

A. Ogimoto $\cdot$ M. Hamada $(\bowtie) \cdot$ K. Hiwada

The Second Department of Internal Medicine, Ehime University School of Medicine, Shigenobu, Onsen-gun, Ehime 791-0295, Japan

Tel. +81-89-960-5302; Fax +81-89-960-5306

e-mail:mhamada@m.ehime-u.ac.jp

J. Nakura · T. Miki

Department of Geriatric Medicine, Ehime University School of

Medicine, Ehime, Japan
2000). In addition, patients with HCM have markedly impaired left ventricular diastolic function (Rosing et al. 1979; Hamada et al. 2001). Thus, AF leads to clinical decline in patients with HCM because of the loss of atrial contribution to filling of the hypertrophied and stiff left ventricle. Moreover, the coagulation system is markedly activated in HCM (Yamamoto et al. 1995). Therefore, patients with AF have a markedly increased risk of clinical decline and thromboembolism (Hamada et al. 1985; Shigematsu et al. 1995).

The renin-angiotensin system (RAS) is known to play a very important role in many cardiovascular diseases (Marian et al. 1993; Raynolds et al. 1993; Lechin et al. 1995; Lindpaintner et al. 1995; Yoneya et al. 1995; Pfeufer et al. 1996; Malik et al. 1997; Tabara et al. 2001) and to influence occurrence of thromboembolism (González Ordóñez et al. 2000). Circulating levels of angiotensin-converting enzyme (ACE) are linked to a 287-base pair insertion/deletion (I/D) polymorphism in intron 16 of the $A C E$ gene, which accounts for $50 \%$ of serum ACE level variability (Rigat et al. 1990). In addition, plasma ACE activity is significantly higher in individuals with the $\mathrm{D}$ allele than in individuals with the I allele (Rigat et al. 1990).

However, the relation between AF and the ACE I/D polymorphism has not been fully investigated. Thus, the purpose of this study was to determine the relation between $A C E$ genotypes and the occurrence of $\mathrm{AF}$ in patients with $\mathrm{HCM}$

\section{Patients and methods}

Study population

Analyses of DNA and measurement of plasma atrial natriuretic peptide (ANP) levels and brain natriuretic peptide (BNP) levels were performed between March 2000 and August 2000 on blood samples of patient volunteers. The study protocols were approved by the Ethics Committee of Ehime University School of Medicine, and written and informed consent was obtained from each subject. 
One hundred thirty-eight patients diagnosed with HCM at Ehime University Hospital between 1977 and 2000 were enrolled in this study. Of these patients, 26 were diagnosed with $\mathrm{AF}$ and 112 were diagnosed with sinus rhythm (SR); thus, there were two groups of study patients. HCM was diagnosed on the basis of echocardiographic criteria defined as the presence of left ventricular hypertrophy in the absence of other causes for hypertrophy. Patients were excluded from this study if they had undergone cardiac surgery. These patients also met the definition and classification proposed by the 1995 World Health Organization/ International Society and Federation of Cardiology Task Force (Richardson et al. 1996). Age at initial clinical evaluation ranged between 13 and 75 years (mean $52 \pm 13$ years). Age at the most recent evaluation ranged between 14 and 91 years (mean $63 \pm 13$ years). The total follow-up period ranged between 8 and 276 months (mean $128 \pm 85$ months).

\section{Echocardiographic study}

M-mode and two-dimensional echocardiography were performed in all patients via an SSD 870 or 9000 imaging system (Aloka, Tokyo, Japan) with a $2.5-$ or a $3.5-\mathrm{MHz}$ transducer. M-mode echocardiograms were recorded on a strip-chart recorder at a paper speed of $50 \mathrm{~mm} / \mathrm{s}$. From the M-mode echocardiographic study, the following conventional variables were measured according to the criteria of the American Society of Echocardiography: left atrial dimension (LAD) at end-systole, interventricular septal thickness and left ventricular posterior wall thickness at end-diastole (IVST and PWT), left ventricular dimensions at end-diastole and end-systole (LVDd and LVDs), and percent fractional shortening (\%FS).

\section{Measurement of plasma ANP and BNP levels}

Plasma ANP and BNP levels were determined as reported previously (Hamada et al. 1998). Normal plasma ANP and BNP values in our institution are $<43.0 \mathrm{pg} / \mathrm{ml}$ and $<17.0 \mathrm{pg} / \mathrm{ml}$, respectively.

\section{Determination of $A C E$ genotypes}

Genomic DNA was extracted from peripheral blood samples with an extraction kit (Qiagen, Hilden, Germany). Gene polymorphisms of ACE I/D were determined by standard methods (Lindpaintner et al. 1995). In brief, the I/D polymorphism of the $A C E$ gene was identified by polymerase chain reaction (PCR) amplification performed with a set of oligonucleotide primers flanking the polymorphic site in intron 16 (5'-GCC CTG CAG GTG TCT GCA GCA TGT-3' and 5'-GGA TGG CTC TCC CCG CCT TGT TCT C-3'). To avoid mistyping, each sample found to have the DD genotype was subjected to a second, independent round of PCR amplification with a primer pair that recognized an insertion-specific sequence (5'-TGG GAC CAC AGC GCC CGC CAC TAC-3' and 5'-TCG CCA GCC
CTC CCA TGC CCA TAA-3'). ACE genotypes of patients with HCM were compared with those of healthy Japanese subjects that have been reported elsewhere (Tabara et al. 2001).

\section{Statistical analysis}

All statistical analyses were performed on a personal computer with SPSS Version 10.0J for Windows (SPSS, Inc., Chicago, IL, USA). Summary data are expressed as mean $\pm \mathrm{SD}$ values. To test for Hardy-Weinberg equilibrium, the expected genotype numbers were calculated from the allele frequencies, and deviation from the observed genotype numbers was determined by chi-square test. To analyze differences between $\mathrm{D}$ allele carriers and noncarriers, the ID and DD genotypes were pooled into one group. Because of the non-normal distribution of most parameters, differences between the AF group and the SR group were tested by Mann-Whitney $U$ test. Association between polymorphisms and case/control status was tested by logistic regression analysis controlling for age, gender, and other variables. Odds ratios (ORs) were estimated with $95 \%$ confidence intervals as measures of risk. Kaplan-Meier curves were constructed to examine time to the first $\mathrm{AF}$ event and compared by log-rank test. A probability value of less than 0.05 was considered statistically significant.

\section{Results}

Characteristics of the study population

Characteristics are shown per group in Table 1. No significant differences in age, sex ratio, body mass index, systolic and diastolic blood pressures, LVDd, LVDs, \%FS, and IVST + PWT were found between the two groups. Significant differences in the follow-up period, LAD, ANP, BNP, and incidence of thromboembolism were detected between the two groups.

\section{Documentation of AF}

The AF group consisted of 18 patients with chronic AF (defined as AF sustained for $>6$ months) and 8 with paroxysmal AF (lasting for $>1 \mathrm{~h}$ but not persisting for 6 months). Age at the first documented AF was $59 \pm 10$ years. AF was present in 4 patients at initial clinical evaluation. Twentytwo patients developed AF 12 to 216 months (median $93 \pm$ 61 months) after the diagnosis of HCM. The onset of AF was associated with thromboembolic episodes in 15 of 26 (58\%) patients. In addition, thromboembolic events might have occurred during the first documented episode of paroxysmal AF in 4 of 8 patients $(50 \%)$ diagnosed with paroxysmal AF. Cerebral embolism occurred in 14 (93\%) of 15 patients with thromboembolism. There was no significant difference in the incidence of thromboembolism between patients with paroxysmal AF (50\%) and those with chronic 
Table 1. Clinical data per study group

\begin{tabular}{|c|c|c|c|}
\hline & $\begin{array}{l}\text { Total HCM patients } \\
(n=138)\end{array}$ & $\begin{array}{l}\text { AF group } \\
(n=26)\end{array}$ & $\begin{array}{l}\text { SR group } \\
(n=112)\end{array}$ \\
\hline Age at the most recent evaluation (years) & $63 \pm 13$ & $66 \pm 10$ & $62 \pm 14$ \\
\hline Age at initial evaluation (years) & $52 \pm 13$ & $53 \pm 9$ & $52 \pm 14$ \\
\hline Duration of follow-up (months) & $128 \pm 85$ & $159 \pm 81 *$ & $121 \pm 84$ \\
\hline Male sex $(\%)$ & $104(75 \%)$ & $22(85 \%)$ & $82(73 \%)$ \\
\hline Body mass index & $24 \pm 4$ & $24 \pm 3$ & $24 \pm 4$ \\
\hline Systolic blood pressure $(\mathrm{mmHg})$ & $129 \pm 19$ & $124 \pm 19$ & $130 \pm 19$ \\
\hline Diastolic blood pressure $(\mathrm{mmHg})$ & $76 \pm 11$ & $74 \pm 10$ & $77 \pm 11$ \\
\hline HOCM & $33(24 \%)$ & $5(19 \%)$ & $28(25 \%)$ \\
\hline HNCM & $105(76 \%)$ & $21(81 \%)$ & $84(75 \%)$ \\
\hline LAD $(\mathrm{mm})$ & $40 \pm 8$ & $46 \pm 8^{*}$ & $38 \pm 7$ \\
\hline IVST + PWT (mm) & $23 \pm 5$ & $23 \pm 3$ & $22 \pm 5$ \\
\hline LVDd (mm) & $47 \pm 5$ & $48 \pm 3$ & $47 \pm 5$ \\
\hline LVDs (mm) & $30 \pm 6$ & $32 \pm 5$ & $29 \pm 6$ \\
\hline$\%$ FS $(\%)$ & $37 \pm 9$ & $35 \pm 7$ & $38 \pm 9$ \\
\hline ANP $(\mathrm{pg} / \mathrm{ml})$ & $67 \pm 76$ & $101 \pm 77^{*}$ & $59 \pm 73$ \\
\hline $\mathrm{BNP}(\mathrm{pg} / \mathrm{ml})$ & $223 \pm 296$ & $379 \pm 314^{*}$ & $187 \pm 281$ \\
\hline Thromboembolism & $15(11 \%)$ & $15(58 \%)^{*}$ & 0 \\
\hline \multicolumn{4}{|l|}{ Treatment } \\
\hline Beta-blocker & $56(41 \%)$ & $13(50 \%)$ & $43(38 \%)$ \\
\hline Calcium antagonist & $105(76 \%)$ & $22(85 \%)$ & $83(74 \%)$ \\
\hline \multicolumn{4}{|c|}{$\begin{array}{l}\text { Values are mean } \pm \text { SD } \\
\text { HCM, Hypertrophic cardiomyopathy; AF, atrial fibrillation; SR, sinus rhythm; HOCM, hyper- } \\
\text { trophic obstructive cardiomyopathy; HNCM, hypertrophic nonobstructive cardiomyopathy; } \\
\text { LAD, left atrial dimension; IVST, interventricular spetal thickness; PWT, posterior wall thick- } \\
\text { ness; LVDd, left ventricular dimension at end-diastole; LVDs, left ventricular dimension at end- } \\
\text { systole; FS, fractional shortening; ANP, atrial natriuretic peptide; BNP, brain natriuretic peptide } \\
* P<0.05 \text { Mann-Whitney } U \text { test (vs. SR group) }\end{array}$} \\
\hline
\end{tabular}

Table 2. Frequencies of ACE genotypes in HCM patients

\begin{tabular}{lcccc}
\hline $\begin{array}{l}\text { Genotype and } \\
\text { allele frequencies }\end{array}$ & $\begin{array}{l}\text { Healthy Japanese } \\
(n=205)\end{array}$ & $\begin{array}{l}\text { HCM } \\
(n=138)\end{array}$ & $\begin{array}{l}\text { AF group } \\
(n=26)\end{array}$ & $\begin{array}{l}\text { SR group } \\
(n=112)\end{array}$ \\
\hline DD & $27(13 \%)$ & $21(15 \%)$ & $3(12 \%)^{*}$ & $18(16 \%)$ \\
ID & $95(46 \%)$ & $64(46 \%)$ & $7(27 \%)^{*}$ & $57(51 \%)$ \\
II & $83(41 \%)$ & $53(38 \%)$ & $16(62 \%)^{* \dagger}$ & $37(33 \%)$ \\
DD + ID & $122(59 \%)$ & $85(62 \%)$ & $10(38 \%) \dagger$ & $75(67 \%)$ \\
D allele & 0.36 & 0.38 & $0.25 *$ & 0.42 \\
I allele & 0.64 & 0.62 & $0.75^{*}$ & 0.58 \\
\hline
\end{tabular}

Numbers are number of patients. Percentages are shown in parentheses

ACE, Angiotensin-converting enzyme; all other abbreviations as in Table 1

$* P<0.03, \dagger P<0.01$ by chi-square test

AF (61\%). None of the patients in the SR group had systemic thromboembolism.

\section{Frequencies of alleles and genotypes}

The PCR results were evaluated by two independent investigators. All ambiguous samples were analyzed a second time. Table 2 shows distribution of the $A C E$ genotypes and allele frequencies in the 138 study patients. Frequencies of the $A C E$ genotypes were virtually identical to those predicted by Hardy-Weinberg equilibrium. Distribution of the respective $A C E$ genotypes in the $\mathrm{AF}$ group and in the $\mathrm{SR}$ group was in Hardy-Weinberg equilibrium. There was a significant difference in the distribution of $A C E$ genotypes between the $\mathrm{AF}$ and $\mathrm{SR}$ groups, however (chi-square = 7.36; $P<0.03)$.
In addition, in a dominant $\mathrm{D}$ allele model (DD and ID genotypes vs. II genotype), there was a significant difference in genotypes between the AF group and the SR group (chi-square $=7.25 ; P<0.01$ ). However, in a recessive $\mathrm{D}$ allele model (DD genotype vs. ID and II genotypes) there was no significant difference in $A C E$ genotypes between the AF and SR groups.

\section{Risk factors for $\mathrm{AF}$}

Table 3 shows ORs for AF in patients with $\mathrm{HCM}$ determined by logistic analysis. The odds of AF occurring in patients with the II genotype were 3.2-fold greater in the univariate model and 4.8 -fold greater in the multivariate model than that in patients with the ID or DD genotypes. 
Table 3. Odds ratios for AF in patients with HCM

\begin{tabular}{|c|c|c|c|c|}
\hline & \multicolumn{2}{|l|}{ Univariate model } & \multicolumn{2}{|l|}{ Multivariate model } \\
\hline & $\begin{array}{l}\text { Odds ratio } \\
\text { ( } 95 \% \text { confidence interval) }\end{array}$ & $P$ value & $\begin{array}{l}\text { Odds ratio } \\
\text { (95\% confidence interval) }\end{array}$ & $P$ value \\
\hline Age & $1.03(0.99-1.06)$ & 0.17 & & \\
\hline Male sex & $2.01(0.64-6.32)$ & 0.23 & & \\
\hline Body mass index & $1.02(0.90-1.15)$ & 0.80 & & \\
\hline HOCM & $0.71(0.25-2.07)$ & 0.54 & & \\
\hline II genotype (vs DD + ID) & $3.24(1.34-7.84)$ & 0.009 & $4.80(1.45-15.9)$ & 0.01 \\
\hline LVDd & $1.07(0.99-1.17)$ & 0.11 & & \\
\hline LVDs & $1.07(1.00-1.14)$ & 0.06 & & \\
\hline$\% \mathrm{FS}$ & $0.96(0.91-1.01)$ & 0.09 & & \\
\hline IVST + PWT & $1.03(0.94-1.11)$ & 0.55 & & \\
\hline LAD & $1.17(1.09-1.25)$ & $<0.0001$ & $1.16(1.07-1.26)$ & 0.001 \\
\hline ANP & $1.00(1.00-1.02)$ & 0.04 & $1.01(1.00-1.02)$ & 0.003 \\
\hline BNP & $1.00(1.00-1.00)$ & 0.01 & & \\
\hline
\end{tabular}

Odds ratios determined by logistic regression analysis

Abbreviations as in Table 1 and Table 2

Probability of remaining free of AF

For 134 patients without evidence of established AF at initial evaluation, Kaplan-Meier curves examining the time to the first event of documented AF showed that the probability of remaining free of AF was significantly lower in patients with the II genotype than in patients with the DD genotype or the ID genotype $(P<0.05$; Fig. $1 \mathrm{~A})$ or when considering the DD and ID genotypes together $(P=0.01$; Fig. 1 B).

\section{Discussion}

Our study is the first to show a relation between the ACE $\mathrm{I} / \mathrm{D}$ polymorphism and AF in patients with HCM. Our results indicate that the II genotype may be a risk factor for development of AF in Japanese patients with HCM. Moreover, our results suggest that the $A C E$ gene plays an important role in the occurrence of AF in patients with HCM.

\section{AF in patients with $\mathrm{HCM}$}

Several investigators (Spirito et al. 1992; Cecchi et al. 1995; Shigematsu et al. 1995; Higashikawa et al. 1997; Maron et al. 2000 ) have reported the occurrence of $\mathrm{AF}$ in $10 \%$ to $28 \%$ of patients with HCM 7 to 10 years after initial diagnosis. The incidence of $\mathrm{AF}$ in the present study (19\%) was almost identical to that of these previous studies. In our study, $23 \%$ of the AF group had left ventricular obstruction, which was not significantly different from that of the SR group. In addition, there was no significant difference in IVST + PWT between the AF and SR groups. Duration of the follow-up period, which means an increase in age of patients, may be one of determinants for AF. Spirito et al. (1992) reported that chronic AF occurred most often in the nonobstructive type HCM with relatively mild ventricular hypertrophy. Previously, we reported that the functional
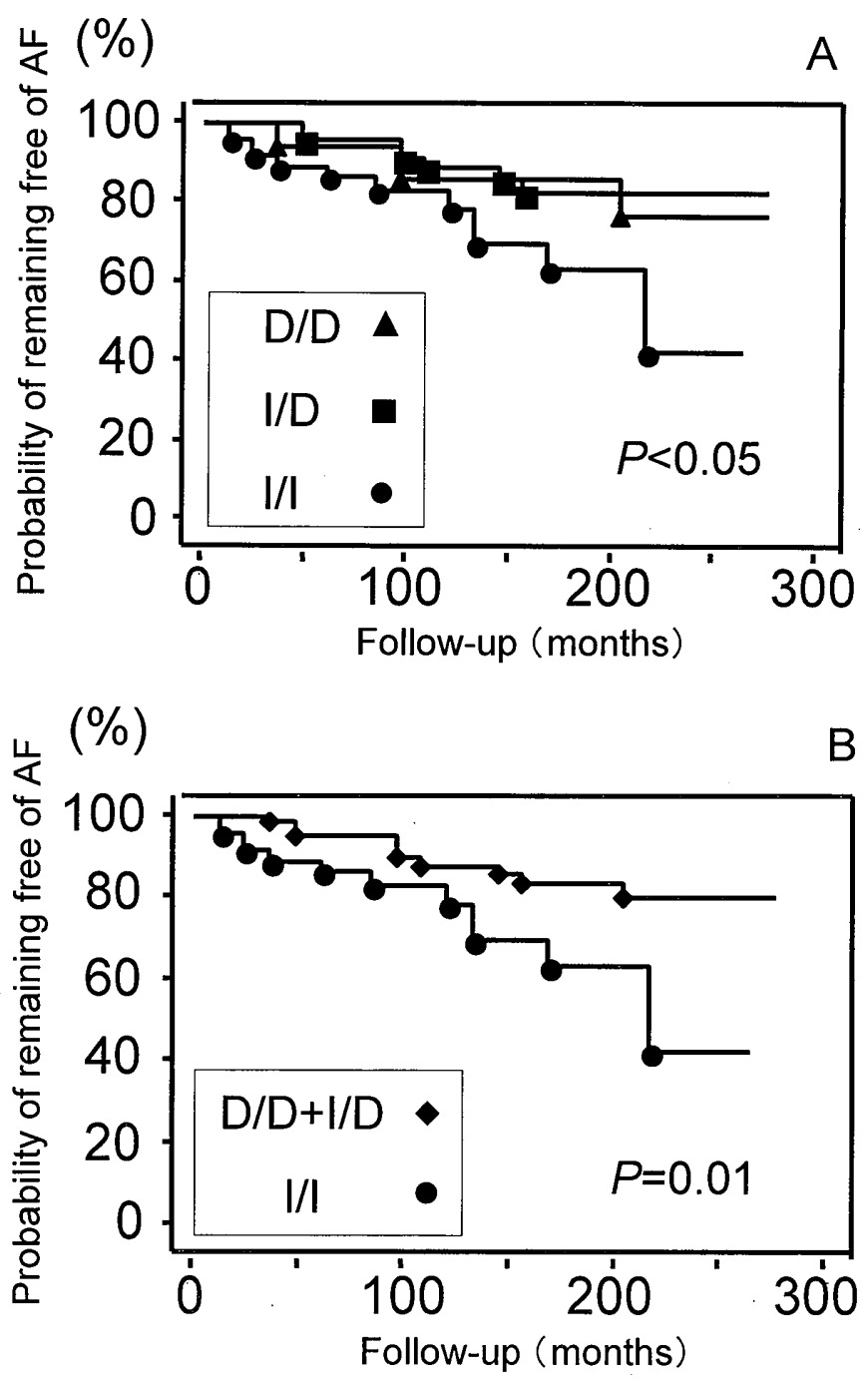

Fig. 1A,B. Percent cumulative probability (Kaplan-Meier estimates) of remaining free of atrial fibrillation (AF) during the follow-up period in study patients without evidence of established AF at initial evaluation 
chamber-size of the left ventricle in patients with HCM was closely related to the size of left atrium and left ventricular end-diastolic pressure (Shigematsu et al. 1995). Thus, the severity of left ventricular diastolic dysfunction may be another factor for AF. Recently, we reported that the class Ia antiarrhythmic drug cibenzoline can attenuate the left ventricular pressure gradient (Hamada et al. 1997) and directly improve left ventricular diastolic dysfunction in HCM (Hamada et al. 2001). Thus, the chronic effect of cibenzoline on left ventricular diastolic function may lessen the risks for $\mathrm{AF}$.

Recent studies (Pedersen et al. 1999; Goette et al. 2000; Nakashima et al. 2000) suggest that AF is associated with activation of the atrial RAS. According to these findings, the DD genotype is associated with activation of the RAS and is likely to be a risk factor for AF. However, our results do not support this hypothesis in patients with HCM. To our knowledge, there is no report associating the ACE polymorphisms and $\mathrm{AF}$ in patients with cardiovascular disease. In patients with lone $\mathrm{AF}$, distribution of the $A C E$ genotypes is not statistically different from that of healthy volunteers (Yamashita et al. 1997).

\section{Allele frequencies of the $A C E$ gene}

Our study showed that the frequency of the D allele was 0.38 in Japanese patients with HCM, as observed in previous reports (Yoneya et al. 1995; Tabara et al. 2001). However, the D allele frequency of Japanese HCM patients was markedly lower than that of Caucasian HCM patients (Marian et al. 1993; Pfeufer et al. 1996). Although several studies (Marian et al. 1993; Yoneya et al. 1995; Pfeufer et al. 1996) showed that the D allele occurred at a higher frequency in HCM patients than in control subjects, the allele frequency of our HCM patients did not differ significantly from that of previously reported healthy Japanese (Tabara et al. 2001).

\section{$A C E$ I allele and deterioration toward AF}

The exact mechanisms by which AF tends to develop in patients with the II genotype remain to be determined. The RAS has an important role in cardiovascular homeostasis (Malik et al. 1997). It regulates sodium balance and intravascular volume and, in addition, interacts with other blood pressure control mechanisms including the sympathetic nervous system and baroreflexes (Reid 1992). Patients with HCM usually have small left ventricular cavity size due to hypertrophy, and thus, reduction of intravascular volume seems to be related to hypotension. In addition, exercise hypotension due to inappropriate peripheral vasodilation was demonstrated in patients with HCM (Frenneaux et al. 1990). Therefore, activation of the RAS may be more protective to maintain intravascular volume and systemic circulation in HCM patients. In fact, ACE inhibition in patients with HCM is known to aggravate hemodynamics (Kyriakidis et al. 1998) and lead to hypotension and excessive systolic emptying (Topol et al. 1985). Patients with the
II genotype may be in a circulatory ACE inhibitory state. Thomson et al. (1998) suggested that hypotension during central volume unloading might provide an additional or alternate trigger for arrhythmia in some patients with HCM. Thus, a systemic irritable condition associated with an ACE inhibitory state in HCM patients may be related to the high occurrence of AF in patients with the II genotype.

\section{Study limitations}

We did not measure plasma levels of renin, ACE, angiotensin II, or bradykinin in evaluating RAS. We did not evaluate the left ventricular function at the patient's initial visit to our hospital. Therefore, we could not evaluate changes in left ventricular hemodynamics. The number of patients in our study was relatively small; therefore, these findings could have resulted from a spurious or chance association. Our results should be compared with those of longitudinal studies in various populations. Further molecular, biological, and clinical studies are needed to clarify the relation between ACE polymorphism and AF in patients with HCM.

\section{References}

Cecchi F, Olivotto I, Montereggi A, Santoro G, Dolara A, Maron BJ (1995) Hypertrophic cardiomyopathy in Tuscany: clinical course and outcome in an unselected regional population. J Am Coll Cardiol 26:1529-1536

Frenneaux MP, Counihan PJ, Caforio ALP, Chikamori T, McKenna WJ (1990) Abnormal blood pressure response during exercise in hypertrophic cardiomyopathy. Circulation 82:1995-2002

Goette A, Staack T, Röcken C, Arndt M, Geller JC, Huth C, Ansorge S, Klein HU, Lendeckel U (2000) Increased expression of extracellular signal-regulated kinase and angiotensin-converting enzyme in human atria during atrial fibrillation. J Am Coll Cardiol 35:16691677

González Ordóñez AJ, Fernández Carreira JM, Medina Rodríguez JM, Martín Sánchez L, Alvarez Díaz R, Alvarez Martinez MV, Coto Garcia E (2000) Risk of venous thromboembolism associated with the insertion/deletion polymorphism in the angiotensin-converting enzyme gene. Blood Coagul Fibrinolysis 11:485-490

Hamada M, Matsubara W, Tomita N, Miyauchi Y, Kokubu T (1985) Left atrial mobile thrombus in hypertrophic cardiomyopathy. Am J Cardiol 56:812-814

Hamada M, Shigematsu Y, Ikeda S, Hara Y, Okayama H, Kodama K, Ochi T, Hiwada K (1997) Class Ia antiarrhythmic drug cibenzoline: a new approach to the medical treatment of hypertrophic obstructive cardiomyopathy. Circulation 96:1520-1524

Hamada M, Shigematsu Y, Kawakami H, Minamino N, Kangawa K, Matsuo H, Hiwada K (1998) Increased plasma levels of adrenomedullin in patients with hypertrophic cardiomyopathy: its relation to endothelin-1, natriuretic peptides and noradrenaline. Clin Sci 94:21-28

Hamada M, Shigematsu Y, Hara Y, Suzuki M, Ohtsuka T, Hiasa G, Ogimoto A, Saeki H, Suzuki J, Hiwada K (2001) Antiarrhythmic drug, cibenzoline, can directly improve the left ventricular diastolic function in patients with hypertrophic cardiomyopathy. Jpn Circ J 65:531-538

Higashikawa M, Nakamura Y, Yoshida M, Kinoshita M (1997) Incidence of ischemic strokes in hypertrophic cardiomyopathy is markedly increased if complicated by atrial fibrillation. Jpn Circ J 61:673-681

Kyriakidis M, Triposkiadis F, Dernellis J, Androulakis AE, Mellas P, Kelepeshis GA, Gialafos JE (1998) Effects of cardiac versus circula- 
tory angiotensin-converting enzyme inhibition on left ventricular diastolic function and coronary blood flow in hypertrophic obstructive cardiomyopathy. Circulation 97:1342-1347

Lechin M, Quiñones MA, Omran A, Hill R, Yu QT, Rakowski H, Wigle D, Liew CC, Sole M, Roberts R, Marian AJ (1995) Angiotensin-I converting enzyme genotypes and left ventricular hypertrophy in patients with hypertrophic cardiomyopathy. Circulation 92:1808-1812

Lindpaintner K, Pfeffer MA, Kreutz R, Stampfer MJ, Grodstein F, LaMotte F, Buring J, Hennekens CH (1995) A prospective evaluation of an angiotensin-converting-enzyme gene polymorphism and the risk of ischemic heart disease. N Engl J Med 332:706-711

Malik FS, Lavie CJ, Mehra MR, Milani RV, Re RN (1997) Reninangiotensin system: genes to bedside. Am Heart J 134:514-526

Marian AJ, Yu QT, Workman R, Greve G, Roberts R (1993) Angiotensin-converting enzyme polymorphism in hypertrophic cardiomyopathy and sudden cardiac death. Lancet 342:10851086

Maron BJ, Olivotto I, Spirito P, Casey SA, Bellone P, Gohman TE, Graham KJ, Burton DA, Cecchi F (2000) Epidemiology of hypertrophic cardiomyopathy-related death. Revisited in a large nonreferral-based patient population. Circulation 102:858-864

Nakashima H, Kumagai K, Urata H, Gondo N, Ideishi M, Arakawa K (2000) Angiotensin II antagonist prevents electrical remodeling in atrial fibrillation. Circulation 101:2612-2617

Pedersen OD, Bagger H, Køber L, Torp-Pedersen C (1999) Trandolapril reduces the incidence of atrial fibrillation after acute myocardial infarction in patients with left ventricular dysfunction. Circulation 100:376-380

Pfeufer A, Osterziel KJ, Urata H, Borck G, Schuster H, Wienker T, Dietz R, Luft FC (1996) Angiotensin-converting enzyme and heart chymase gene polymorphisms in hypertrophic cardiomyopathy. Am J Cardiol 78:362-364

Raynolds MV, Bristow MR, Bush EW, Abraham WT, Lowes BD, Zisman LS, Taft CS, Perryman MB (1993) Angiotensin-converting enzyme DD genotype in patients with ischaemic or idiopathic dilated cardiomyopathy. Lancet 342:1073-1075

Reid IA (1992) Interactions between ANG II, sympathetic nervous system and baroreceptor reflexes in regulation of blood pressure. Am J Physiol 262: E763-778
Richardson P, McKenna W, Bristow M, Maisch B, Mautner B, O'Connell J, Olsen E, Thiene G, Goodwin J, Gyarfas I, Martin I, Nordet P (1996) Report of the 1995 World Health Organization/ International Society and Federation of Cardiology Task Force on the definition and classification of cardiomyopathies. Circulation 93:841-842

Rigat B, Hubert C, Alhenc-Gelas F, Cambien F, Corvol P, Soubrier F (1990) An insertion/deletion polymorphism in the angiotensin I-converting enzyme gene accounting for half the variance of serum enzyme levels. J Clin Invest 86:1343-1346

Rosing DR, Kent KM, Borer JS, Seides SF, Maron BJ, Epstein SE (1979) Verapamil therapy: a new approach to the pharmacologic treatment of hypertrophic cardiomyopathy. I. Hemodynamic effects. Circulation 60:1201-1207

Shigematsu Y, Hamada M, Mukai M, Matsuoka H, Sumimoto T, Hiwada K (1995) Mechanism of atrial fibrillation and increased incidence of thromboembolism in patients with hypertrophic cardiomyopathy. Jpn Circ J 59:329-336

Spirito P, Lakatos E, Maron BJ (1992) Degree of left ventricular hypertrophy in patients with hypertrophic cardiomyopathy and chronic atrial fibrillation. Am J Cardiol 69:1217-1222

Tabara Y, Kohara K, Nakura J, Miki T (2001) Risk factor-gene interaction in carotid atherosclerosis: effect of gene polymorphisms of renin-angiotensin system. J Hum Genet 46:278-284

Thomson HL, Morris-Thurgood J, Atherton J, Frenneaux M (1998) Reduced cardiopulmonary baroreflex sensitivity in patients with hypertrophic cardiomyopathy. J Am Coll Cardiol 31:1377-1382

Topol EJ, Traill TA, Fortuin NJ (1985) Hypertensive hypertrophic cardiomyopathy of the elderly. N Engl J Med 312:277-283

Yamamoto K, Ikeda U, Furuhashi K, Irokawa M, Nakayama T, Shimada K (1995) The coagulation system is activated in idiopathic cardiomyopathy. J Am Coll Cardiol 25:1634-1640

Yamashita T, Hayami N, Ajiki K, Oikawa N, Sezaki K, Inoue M, Omata M, Murakawa Y (1997) Is ACE gene polymorphism associated with lone atrial fibrillation? Jpn Heart J 38:637-641

Yoneya K, Okamoto H, Machida M, Onozuka H, Noguchi M, Mikami T, Kawaguchi H, Murakami M, Uede T, Kitabatake A (1995) Angiotensin-converting enzyme gene polymorphism in Japanese patients with hypertrophic cardiomyopathy. Am Heart J 130:10891093 